ipecacuanha and squill emetics, and calomel and James's powder; and I have every reason to think that the Cupri Sulphas was the main remedy in effecting a speedy cure; but it seems to me to require constant watching, (as of course does also the complaint itself,) for there appears to be great collapse and paleness induced, with retching and usually purging of green stools. I first received the hint respecting this remedy from "Braithwaite's Retrospect," rol. 8, Art. 28, by Dr. Schwabe, and found the effects exactly the same as they are described in this article. I am disposed, howerer, also to attach some importance to the rpplication of the tincture of iodine at the same time with the othér remedies.

\section{CASE OF POISONING BY EXTRACT OF BELLADONNA.}

By Јонn M. Baxxer, Esq., F.R.C.S., Senior Surgeon to the Northern Hospital, Liverpool.

T. N., aged nine, was affected, on the 27 th of Oetober, 1846, with mild scarlatica. The fever ran its course in about eight days. On the third day after the disappearance of the eruption, jaundice presented itself; the skin was highly tinged, the stools white, and the urine bighly impregnated with bile. Although the eruption disappeared, it was not until the 27 th of December that the process of desquamation was completed.

At the latter end of December (the 20th,) I was requested to see Master $\mathrm{N}$., in consequence of the obstinacy of the jaundice, and considered it necessary to prescribe an ounce of extract of dandelion, to which was to be added two wine-glassfuls of water. Of this mixture he was ordered to take three tea-spoonfuls three times a day, and did so regularly until the 4 th of January, when the pot which contained the extract was again sent to the druggist to be re-filled, and at right the water added as usual. For some reason unassigned, the night dose was not adıinistered.

At eleven, a.m., of the 5 th, the first dose of the nixture or fluid extract was given by the mother, at which time the boy was in good spirits, and in every respect much better; the secretion of bile was passing into the bowels; his appetite was improved, and we had good reason to consider him fast approaching to recorery. The mother left the patient in the charge of her maid for a few hours, having occasion to absent herself for that length of time. Slue had not been gone more than half an hour, when the servant states that she observed a strange and unnatural appearance about the boy, bu: did not feel any alarm, nor did she think it necessary to state the circunstance to the family until about half an hour later, (twelve o'clock,) when the boy began to talk rery incoherently, and was extremely restless; the delirium became very high, but quickly passed off, when he became quiet, though constantly affected with twitchings in the arms. Not knowing what to do, and ascribing the state to exlaustion for the want of food, she administered a large quantity of hot tea, which caused great sickness.

When I saw the case at three o'clock, I was told that the boy had romited twice after taking the tea, and had thrown from the stomach a large quantity, which had not been preserved. The patient appeared in a comatose state; the breathing was slow; the eyes fixed; the pupils dilated to the fullest extent, and insensible to the adinission of light; the hands and feet were cold and moist ; the pulse was remarkably quick and weak, and slightly intermittent. If roused the patient tried to seize hold of the person touching him, and would shout, and occasionally laugh loudly, and weuld throw out the arms as if striking at an object; he could not articulate, though he often muttered as if attempting to express something; there was twitching of the flexor muscles of the arms, particularly of the left; the frequently seized hold of the bed-clothes, and attempted to draw them up, as if to cover his head. I ordered wine and hot water to be given freely; warmth to be applied to the surface, and cold-spirit wash to the head, and a large enema of salt and gruel was administered. After this injection the patient became very restless, constantly trying to get up. Thinking it probable that he wanted to pass stool, we carried hitn to the chair, when he passed large evacuations, which would prove some degree of consciousness. There was great disinclination to swallow fluid; it required more than ordinary force to effect this object. After a considerable excitement, for a minute or two he would fall into a quiet state, scarcely moring; he would suddenly begin to throw about his arms, and strike them forcibly from him, and then seize the bedclothes, and endeavour to draw them over his face and head. The arms occasionally twitched convulsively. I remained with the patient for a considerable time; the first impression was that he had taken some narcotic poison, contuined either in an embrocation or cough mixture. We carefully examined the room, but could not find anything confirmatory of this.

Having explained to the family the great danger the child appeared to be in, and the difficulty $I$ felt in issignirg a cause for the sudden change in the case, Dr. Duncan was requested to meet me in consultation. We met at five o'clock, five hours after the first attack, at which time the symptoms continued as before related, with the exception that the surface generally was warmer. The wine and water had been forced into the mouth, and he had swallowed a considerable quantity, on various occasions

Dr. Duncan was equally at a loss with myself as to the cause of the symptoms; at first he was inclined to attribute them to the jaundice, or some intestinal irritation, but from the fact that the child had been so much better, and the bile beginning to pass into the bowel, at once did away with the first supposition. On questioning the mother (who hạd by this time returned hoine,) we for the first time learnt that fresh medicine had been procured on the previous night, and she did not at the time of mixing it think it quite the same as before On examining the extract we immediately considered it a wrong niedicine, and pronounced it either belladonna or henbane. To make ourselves fully satisfied we visited the druggist who bud furnished it, as well as the former pots of extract. He unhesitatingly acknowledged that he had seut the extract of belladonna, and for the moment did not appear aware of 
the mistake. It appeared that he had to send out some of the extract of belladonna on the night in question, and the impression on his mind was, that the same extract was wanted for $T$. N., and thus the mistake arose. I mention this circunistance to prove that there is no mistake as to the extract of belladonna being given, nor of the quantity taken.

The mode of treatment was persevered in; the lotion to the head, the wine and water drink, and a powder containing rhubarb and calomel given, which acted freely. The evacuation was dark-coloured, and from the peculiar odour, we considered it to contain a considerable quantity of belladonna. The delirium continued during the night, little rarying from the symptoms enumerated; the pulse became more intermitting and fuller, so that it was thought proper to discontinue the stimulants.

At four, a.m., of the $6 \mathrm{th}$, sleep for the first-time orercame the patient; he slept lightly for two hours, after which the delirium was less violent, the pulse more tranquil, though very intermittent. He again slept lightly until near nine, a.m., and appeared more conscions afterwards; the pupils were still fully dilated, and he did not appear to see oljects clearly, for on taking his hand, he felt with the other hand at what touched him, and laughed very much; he had less disinclination to take fluid, and partook of a small quantity of gruel. During the whole delirium he showed, from his peculinr restlessness, that he either wished to pass water or stool, neither of which passed involuntarily. There was not the least appearance of eruption.

From this time the symptoms gradually disappeared, the pulse became nore regular, the pupils gradually became less dilated, though very irregular in their action; it was not until the expiration of five days that they acted more regularly; at that time the right pupil remained more dilated than the left. He complained for several days of pain in the head and difficulty of vision; he could not see to read with ease for some time, indeed I may say, that it was ten days before he got from under the influence of the poison.

From the calculation made, we consider that at least.thirty grains of the extract of belladonna was given. The belladonna did not appear to bave any effect on the jaundice, beyond the fact of its deranging the system for some days.

\section{Ţospital Meport\%.}

\section{QUEEN'S HOSPITAL, BIRMINGHAM.}

CLINICAL REPORTS OF SURGICAL CASES UNDER THE TREATMENT OF WILLIAM SANDS COX, ESQ.

Bj. Peter Hinckes Bird, one of the Resilent Medical Officers.

(Continued from page 69.)

CASE XXII.

SCROFULOUS CARIES OF THE SPINE.

James Riley, aged 25, labourer, admitted March 25th, 1846, into the Queen's Hospital, Birmingham, under the care of Mr. Sands Cox. He states that rather more than two years ago he first felt a pain in his right side, which afterwards flew to the back; it was treated as a rheumatic pain; he gradually got worse, and eighteen months ago he was obliged to give up his occupation, as he got rery weak, and was sonn tired; the use of his legs was gradually impaired, and his back became weak, and he perceived that the backbone became prominent. He states that his legs have at times been drawn up at nights; his urine dribbled away, and he had not perfect control over defecation; has never had abscesses in the back nor in any other part of the body; had swelling of the submaxillary glands a short time since. He states that he contracted syphilis two years ago, for the cure of which he took mercury; has been under medical treatment for eighteen months; enjoyed good health previously,that is to sar, about two years ago.

He complains of dull aching pain in the dursal region, and of slight tightness across the chest; he cannot stand or walk upright, but is much bent forward; his legs feel numbed and cold, and the sensi. bility is diminished; can retain his water perfectly; urine ratber turbid, of natural quantity ; pulse strong, 86 ; appetite good; has a slight cough; the muscles of his limbs are soft, flabby, and atrophied; has no pain in the arms. On examination of the hack there was found projection of the spinous processes of the midule dorsal rertebræ; there is no abscess there, nor on any part of the body.

Ordered to be cupped on each side of the opine, and to remain in bed in the recumbent posture.

April 3r. About the same; legs still numbed; zppetite indifferent; bowels rather confined.

R. Quinœ Disulph., gr. xij.; Acid. Suiph. dil., dr.j.; Aquæ, Oss. M. Sunat oz. iss., ter die. Pil. Rhei Comp. ij. hora somni sumend.

6th. Better; bowels open; appetite improved.

20th. Much better; can walk in a more erect posture ; appetite improved; cough quite gone; bowels regular; his uine presented this morning an iridescent pellicle; this he states he has noticed frequently befure. On examination of a portion under the microscope, the beautiful prisms of the neutral phosphate, mixed with imperfectly-forined crystals of the neutral phosphate, and a few penniform crystals, with epithelium.

Contin. mist. tonica.

23rd. Bowels rather confined. To take Pil. Rbei Comp. ij., statim.

26th. Complains of pain in the back. To bare an issue applied on each side of the diseased vertebræ.

29th. The sloughs have separated. Tu have the issue kept open by the duily insertion of peas.

May 6 6 h. The issues have discharged freely; feels better; legs not so numbed; the pain has disappeared from the dorsal region, and occupies the lower part of the lumbar, extending from hip to hip; can walk much better.

14th. Can walk upright; pain in the hips not so severe; the urine, which was pale, and of a light amber colour, when examined under the microscope, presented 